\title{
EKOLOŠKO-BIOSISTEMATSKE KARAKTERISTIKE POTOČNOG RAKA AUSTROPOTAMOBIUS TORRENTIUM (SHRANK, 1803.) IZ NAHOREVSKOG POTOKA
}

\section{Ecological and biosystematic characteristics of stone crayfish Austropotamobius torrentium (Shrank, 1803.) from the Nahorevo brook}

\author{
Sadbera Trožić-Borovac ${ }^{1}$, Lejla Deljanin ${ }^{1}$ Mirza Dautbašić ${ }^{2}$
}

\begin{abstract}
The paper is a result of studies on the stone crayfish Austropotamobius torrentium from the Nahorevo stream in the period between August 2006 and May 2007. The analysis also included physical/chemical parameters of water and the content of zoobenthics of the Nahorevo stream. It was determined that the water belongs to the oligo/beta-mesosaprobic category or the II category, clean, with minor quantity of foreign alochton organic matter in the water. By measuring the length of 6 female and 5 male stone crayfishes, it was determined that it varies from 4,5 to $7 \mathrm{~cm}$ in females and 1,54 to $7 \mathrm{~cm}$ in males. The statistical analysis indicated that the mass is the most variable, and the most stable characteristic is the length of the body. The calculated value by Fulton's Conditions Factor (RICKER, 1975) and the Crayfish Constant (ADEGBOYE, 1981) showed that the male crayfish is in better physical shape, which coincides with the results of European research reports. The contribution of the paper is determination of the stone crayfish habitat in Bosnia and Herzegovina which included our country into the IUCN list in 1994.
\end{abstract}

$\underline{\text { Key words: }}$ stone crayfish, Condition factor, quality of water, distribution, habitat, variance

\section{Izvod}

Rad je rezultat izlova jedinki potočnog raka Austropotamobius torrentium iz Nahorevskog potoka u periodu od augusta 2006. do maja 2007. godine. Analiza je obuhvatila i fizičko/hemijske paramtere vode i sastav zoobentosa Nahorevskog potoka. Utvrđeno je da voda spada u kategoriju oligo/betamesosaprobnih ili II kategorije, čista sa manjom količinom alohtone organske materiije u vodotoku. Mjerenjem dužine potočnog raka (šest izlovljenih ženki i pet mužjaka), utvrđeno je da ona varira od 4,5 do $7 \mathrm{~cm}$ kod ženke i 1,54 do $7 \mathrm{~cm}$ kod mužjaka. Statističkom obradom utvrđeno je da

\footnotetext{
${ }^{1}$ Prirodno-matematički fakultet Univerziteta u Sarajevu - Natural-mathematical faculty of the University of Sarajevo

${ }^{2}$ Šumarski fakultet Univerziteta u Sarajevu - Faculty of Forestry University of Sarajevo
} 
najviše varira težina, a najstabilniji karakter je dužina tijela. Izračunata vrijednost Fulton's Conditions Factor (RICKER, 1975) i Crayfish Constant, (ADEGBOYE, 1981) ukazuje da je mužjak u boljem kondicionom stanju, što je i rezultat dosadašnjih istraživanja u Evropi. Doprinos rada je utvrđivanje habitata ili staništa potočnog ili raka kamenjara na prostorima Bosne i Hercegovine, koji je 1994. godine uvršten u IUCN listu za prostor naše države.

Ključne riječí: potočni rak, stepen kondicije, varijansa, kvalitet vode, rasprostranjenje, stanište

\section{Uvod - Introduction}

Sve autohtone vrste iz rodova Astacus Pallas 1772 i Austropotamobius Skorikow 1908 uvrštene su u Crvenu listu (Red List IUCN), a njihova staništa u Habitat Directivu. Ove vrste sa prostorom koje naseljavaju zahtijevaju poseban konzervacijski pristup. U Evropi se istraživanja baziraju na analizi genetičkog materijala, tj. DNK (HUBER, SCHUBERT, 2004). Prema dosadašnjem stupnju istraživanja u evropskim zemljama konstatirane su različite autohtone vrste za različite prostore. Tako su u Hrvatskoj konstatirane četiri autohtone vrste (MAGUIRE at all., 2003), Austriji dvije vrste (FUREDER, SINT, LEITER, DECLARA, 2004), Italiji tri (FUREDER, Sint, Leiter, DeClARA, 2004), Mađarskoj tri vrste Astacus astacus, A. leptodactylus $i$ Austropotamobius torrentium (PUKY, SCHAD, 2004), a za zemlje Skandinavije karakteristična je samo jedna autohtona vrsta, plemeniti rak Astacus astacus L. (Edsmon, TAugBǿL, 2004). Naznačeno je da u Bosni i Hercegovini do danas vodne ekosisteme naseljavaju četiri autohtone vrste: A. astacus, A. leptodactylus, A. torrentium $i$ A. pallipes (KARAMAN, 1976; DEDIĆ, 2005; neobjavljeni podaci). U literaturi, (SKET 1996) navodi da je vrsta Austropotamobius torrentium distribuirana i u Bosni i Hercegovini.Iste je godine uvrštena u IUCN-ovu Crvenu listu za prostore Slovenije, Hrvatske i Bosne i Hercegovine. Rasprostranjenje vrste A. torrentium u Evropi se kreće od $50^{\circ} \mathrm{N}$ na području Njemačke do $41^{\circ} \mathrm{N}$ u Makedoniji i 8 E na rijeci Rajni do oko $24^{\circ}$ E u Rumuniji (LAURENT, 1998). Prema mišljenju MACHINO, SKET I TRONTELJ (2004), vrsta je rasprostranjena još dalje na jug, čak do Grčke. Dosadašnji podaci ukazuju da njegovo rasprostranjenje podrobnije obuhvata sljedeće zemlje na području Euroazije: Austriju, Bosnu i Hercegovinu, Bugarsku, Hrvatsku, Češku, Njemačku, Mađarsku, Makedoniju, Rumuniju, Rusku federaciju, Srbiju, Crnu Goru, Slovačku, Sloveniju i Švicarsku (MAGUIRE et. al., 2003).

U Sloveniji je potočni rak konstatiran u slivu Dunava, rijeci Savi, Dravi i sporadično u Muri (BEDJANIČ, 2004), a u jadranskom slivu je ograničen na slivno područje Idrijice (BERTOK et al., 2003; 2004)

U ovom radu je analiziran Nahorevski potok kao habitat ili stanište utvrđene vrste potočnog raka. Jedinke ulovljene u Nahorevskom potoku su analizirane sa aspekta općih ekoloških uvjeta u kojima egzistiraju. Samim radom je po prvi put naznačen precizan lokalitet njegove distribucije koji nije i jedini što će, svakako, potvrditi i istraživanja koja su u toku. Istraživanja u radu su imala polazište u značaju 
riječnih rakova u sveopćem diverzitetu faune određenog prostora, a i u utvrđivanju autohtonih vrsta i njihovog stupnja očuvanosti i značaja u identifikaciji prostora. Do danas poznavanje ekologije i biologije potočnog raka je nedovoljno i oskudno. Ova činjenica ukazuje na obavezu intenziviranja istraživanja potočnih rakova i na prostoru $\mathrm{BiH}$. Za postizanje naznačenog cilja postavljeni su i sljedeći zadaci:

1. determinacija jedinki potočnog raka ulovljenih u Nahorevskom potoku,

2. sagledavanje općih abiotičkih i biotičkih uvjeta u kojima egzistira ova vrsta,

3. mjerenje osnovnih morfometrijskih karaktera podložnih variranju i utjecaju općih ekoloških uvjeta,

4. sagledavanje stupnja kondicije ulovljenih jedinki,

5. donošenje zaključaka o uvjetima u kojima egzistira potočni rak u Bosni i Hercegovini u komparaciji sa uvjetima njegove egzistencije u Evropi,

6. naznake za potrebe i neophodnost istraživanja potočnih rakova u Bosni i Hercegovini.

\section{Metod rada - Work Method}

U cilju istraživanja potočnog raka (kamenjara) Austropotamobius torrentium izvršen je ulov jedinki iz Nahorevskog potoka (sl.1) u periodu od augusta 2006. do maja 2007. godine, $\mathrm{i}$ to u predvečernjem periodu.

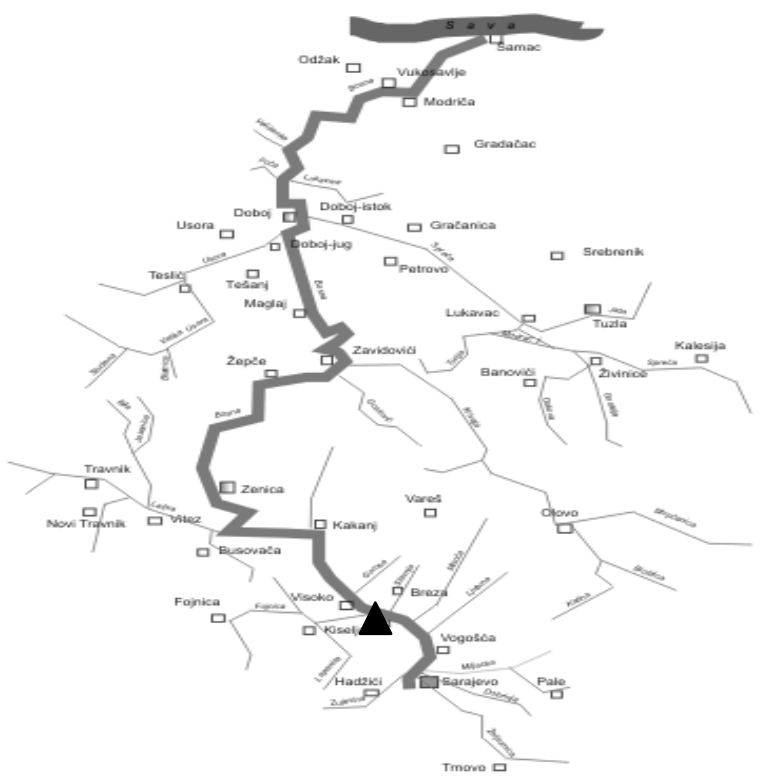

Slika 1. Karta sliva rijeke Bosne sa lokalitetom uzorkovanja u odnosu na grad Sarajevo Figure 1. Map of river Bosnia stream 
Ukupno je izlovljeno 11 jedinki pri čemu je determinirano pet mužjaka i šest ženki (slika 2).

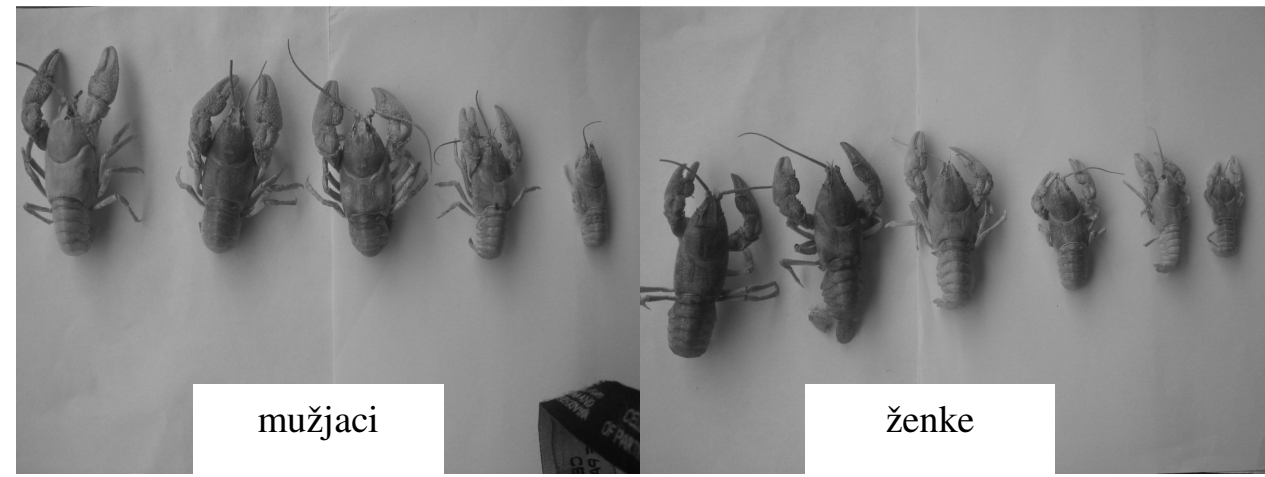

Slika 2. Jedinke mužjaka i ženki potočnog raka ulovljenih u Nahorevskom potoku, od maja 2006. do juna 2007. godine

(Figure 2. Male and female crayfishes taken from Nahorevo brook, from May 2006. to June 2007.)

Na početku uzorkovanja, Institut za hidrotehniku Građevinskog fakulteta u Sarajevu izvršio je analizu fizičko-hemijskih parametara. Pored toga analiziran je i sastav zoobentosa, a rezultati istraživanja prikazani su u tabelama i grafički. Na osnovu sastava zoobentosa data je ocjena kvaliteta vode primjenom saprobnog indeksa (PANTLE-BUCK, 1955) formulom:

$$
\mathrm{S}=\Sigma \mathrm{hxs} / \mathrm{h}
$$

gdje je: $\mathbf{S}$ - saprobni indeks, $\mathbf{h}$ - relativna abundanca, a $\mathbf{s}$ - saprobna vrijednost.

Ulovljene jedinke potočnog raka fiksirane su u $4 \%$ formaldehidu, a obrada je izvršena u laboratoriju Prirodno-matematičkog fakulteta Sarajevo. Determinacija potočnog raka vršena je po ključu KARAMAN, 1976.

U cilju upoznavanja osnovnih bioloških karakteristika raka izvršeno je: mjerenje totalne dužine, totalne težine, dužine karapaksa, širine karapaksa, dužine rostruma, širine rostruma, dužine kliješta i odnos spolova.

Mjerenje je vršeno na svih jedanaest jedinki (pet mužjaka i šest ženki). Za mjerenje težine korištena je laboratorijska vaga i težina je izražena u gramima $(\mathrm{g})$. Dužina i širina pojedinih dijelova izražena je u centimetrima $(\mathrm{cm})$ a mjerenja su vršena linijarom. Nakon izvršenih mjerenja pristupilo se statističkoj obradi podataka. 


\section{Statistička obrada podataka - Statistic analysis of data}

Osnovni statistički podaci dobiveni su prema PETZ (1985):

\section{Srednja vrijednost (artimetička sredina) $X$}

$$
X=\frac{\sum X}{N}
$$

Varijansa $\left(s^{2}\right)$

$$
s^{2}=\frac{\sum\left(x_{i}-x\right)^{2}}{N-1}
$$

\section{Standardna devijacija (S)}

$S=\sqrt{s^{2}}$

\section{Koeficijent varijabilnosti $\left(\mathbf{V}_{\%}\right)$}

$V_{\%}=\frac{100 \cdot S}{X}$

Koeficijent kondicije izračunat je na dva načina:

1. Fulton's Conditions Factor (RICKER, 1975): $\mathbf{F C F}=\mathbf{W} / \mathbf{T}^{3}$ gdje W - težina i $\mathrm{T}$ - totalna dužina

2. Crayfish Constant, (ADEGBOYE, 1981): CC=W/ (TL x CL x CW) gdje je: W - ukupna težina, TL - totalna dužina, CL - dužina karapaksa i W širina karapaksa (STREISSL, HöLD, 2002). Svi rezultati su prikazani tabelarno i grafički.

\section{Rezultati istraživanja - Results of the Research}

Za sagledavanje ekoloških karakteristika potočnog raka mjereni su fizičkohemijski parametri u vodi Nahorevskog potoka, kvalitativno-kvantitativni sastav zoobentosa i tek nakon toga naznačene morfološke karakteristike jedanaest ulovljenih jedinki. Rezultati mjerenja prikazani su odvojeno. 


\section{Opis lokaliteta uzorkovanja - Description of the locality of sampling}

Nakon sastava sa Koševskim potokom, Nahorevski potok se ulijeva u rijeku Miljacku ispod mosta Skenderija. Dužina ovog potoka je oko $1 \mathrm{~km}$ a prosječna širina $2 \mathrm{~m}$, sa maksimalnom dubinom $60 \mathrm{~cm}$. Sediment je kamen srednje veličine sa sedrenim naslagama, obraslost sedimenta biljem je veoma mala (sl. 3), na nekim mjestima svega $5-10 \%$.

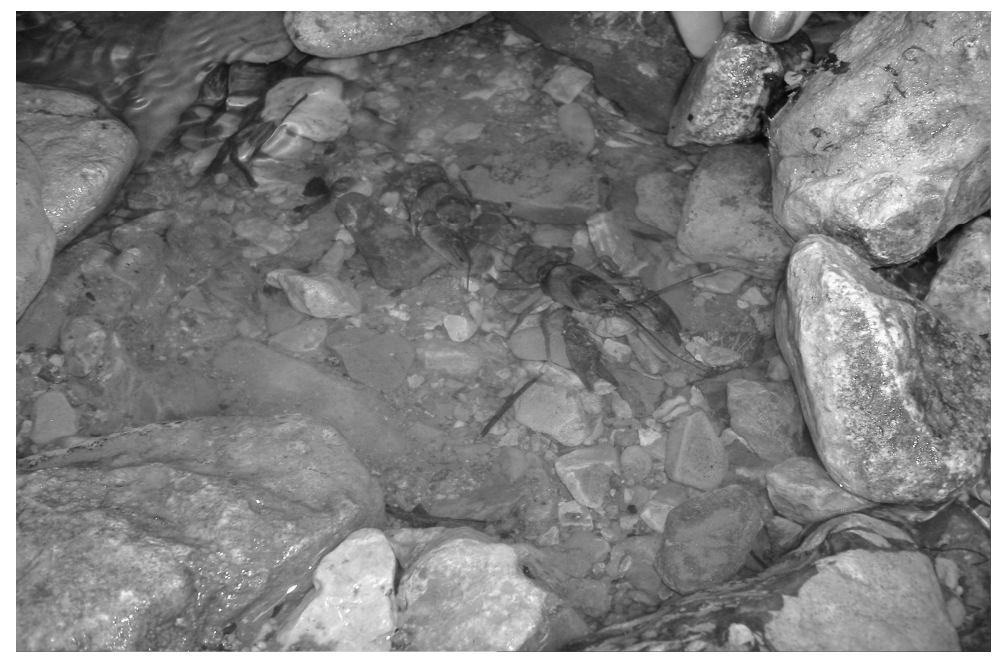

Slika 3. Potočni rak u prirodnim uvjetima lokaliteta istraživanja u Nahorevskom potoku, septembar 2006. godine

Figure 3. Stone crayfish in natural conditions of the research locality in Nahorevo brook, September 2006.

Lijeva obala je visine oko $150 \mathrm{~cm}$ sa gusto razvijenom vegetacijom bukove šume koja je dobro očuvana. Lijevu obalu visine do $180 \mathrm{~cm}$ čine stabla johe, a najveći dio je oivičen mezofilnim kultiviranim livadama koje se aktivno obrađuju. Potok je bujičavog karaktera sa kaskadama i brzim tokom.

\section{Rezultati fizičko-hemijskih mjerenja vode Nahorevskog potoka - Results of physical-chemical measuring of water of Nahorevo brook}

Voda je bez ukusa i mirisa. Mutnoća je povećana kao i količina suspendovane čvrste supstance, rastvorenog oksigena, zasićenosti kisikom (što je dobro), ukupne, karbonatne i nekarbonatne tvrdoće, slobodnog $\mathrm{CO}_{2}$, amonijačnog nitrogena i nitritnog nitrogena te utroška $\mathrm{KMnO}_{4}, \mathrm{BPK}_{5}$ (što nije dobro) i $\mathrm{HCO}_{3}$. Ostale vrijednosti kao što su pH vrijednost, ukupan isparni ostatak na $105^{\circ} \mathrm{C}$, elektroprovodljivost na $20{ }^{\circ} \mathrm{C}$ te količina kalcija, magnezija, kalija, natrija, mangana, željeza, hlorida, nitratnog nitrogena, ortofosfata, silicijdioksida i sulfata u granicama su MDK. 
Mjerenja su rađena na Institutu za hidrotehniku Građevinskog fakulteta u Sarajevu. Na osnovu dobivenih rezultata (tab. 1) može se zapaziti da su svi parametri u granicama nezagađenih voda.

Tabela 1. Vrijednosti fizičko-hemijskih parametara vode iz Nahorevskog potoka Table 1. Values of phisical and chemical parametres of water from Nahorevo brook

\begin{tabular}{|c|c|c|}
\hline Parametar & MDK & 1. \\
\hline Datum (2006. godine) & - & 21.08 . \\
\hline Vrijeme uzimanja uzorka & - & - \\
\hline Protok & - & - \\
\hline Temperatura zraka $\left({ }^{\circ} \mathrm{C}\right)$ & - & - \\
\hline Temperatura vode $\left({ }^{\circ} \mathrm{C}\right)$ & $8-12$ & 10 \\
\hline Miris & bez & bez \\
\hline Ukus & bez & bez \\
\hline Mutnoća (NTU) & 2,4 & 9,1 \\
\hline pH vrijednost & $6,8-8,5$ & 8,02 \\
\hline Ukupan isparni ostatak na $105^{\circ} \mathrm{C}(\mathrm{mg} / \mathrm{l})$ & 1000 & 248 \\
\hline Suspendovane čvrste supstance (mg/l) & bez & 27 \\
\hline Rastvoreni oksigen $\left(\mathbf{m g ~} \mathrm{O}_{2} / \mathrm{l}\right)$ & - & 10,56 \\
\hline Zasićenost oksigenom (\%) & 85 & 102 \\
\hline Elektroprovodljivost na $20^{\circ} \mathrm{C}(\mu \mathrm{S} / \mathrm{cm})$ & 600 & 354 \\
\hline Ukupna tvrdoća $\left(\mathrm{mg} \mathrm{CaCO}_{3} / \mathrm{l}\right)$ & - & 192 \\
\hline Karbonatna tvrdoća $\left(\mathrm{mg} \mathrm{CaCO}_{3} / 1\right)$ & - & 182 \\
\hline Nekarbonatna tvrdoća $\left(\mathrm{mg} \mathrm{CaCO}_{3} / \mathrm{l}\right)$ & - & 10 \\
\hline Kalcij (mg/l) & 200 & 61,7 \\
\hline Magnezij (mg/l) & 50 & 9,2 \\
\hline Kalij (mg/l) & 12 & 0,65 \\
\hline Natrij (mg/l) & 150 & 6,17 \\
\hline Mangan (mg/l) & 0,05 & 0,008 \\
\hline Željezo ukupno $(\mathrm{mg} / \mathrm{l})$ & 0,3 & 0,13 \\
\hline Slobodni karbondioksid (mg/l) & - & 2,64 \\
\hline Kloridi (mg/l) & 200 & 5,0 \\
\hline Amonijačni nitrogen (mg N/l) & $\mathbf{0 , 1}$ & 0,48 \\
\hline Nitratni nitrogen $(\mathrm{mg} \mathrm{N} / \mathrm{l})$ & 10,0 & 1,02 \\
\hline Nitritni nitrogen (mg N/l) & 0,005 & 0,014 \\
\hline $\mathrm{N}-$ Kjeldhl (mg N/l) & & 3,08 \\
\hline Fosfat - orto (mg P/l) & 0,15 & 0,131 \\
\hline Ukupni fosfat (mg P/l) & & 0,145 \\
\hline Silicijdioksid (mg/l) & 20 & 3,46 \\
\hline Sulfat $\left(\mathrm{mg} \mathrm{SO}_{4} / \mathrm{l}\right)$ & 200 & 15,7 \\
\hline Utrošak $\mathrm{KmnO}_{4}(\mathrm{mg} / \mathrm{l})$ & 12 & 14,9 \\
\hline $\mathrm{BPK}_{5}\left(\mathrm{mg} \mathrm{O}_{2} / \mathrm{l}\right)$ & - & 2,48 \\
\hline Hidrokarbonati $\left(\mathrm{HCO}_{3}\right)$ & - & 222,0 \\
\hline
\end{tabular}




\section{Zoobentos Nahorevskog potoka - Zoobentos of Nahorevo brook}

U sastavu zoobentosa Nahorevskog potoka u proljetno-ljetnom periodu konstatirano je 15 taksona sa 60 jedinki (tab.2). Dominantna je zastupljenost insekata iz senzibilnih grupa Plecoptera, Trichoptera i Ephemeroptera. Posebni značaj imaju vrste kamenjarki iz roda Taenopteryx i Perla koje su, prema svojoj saprobnoj vrijednosti, vezane za čiste vode. Fauna vodenih moljaca - Trichoptera predstavljena je vrstama iz familije Hydropsichidae (dvije vrste) koje indiciraju organsko onečišćenje i vrstama iz familje Rhyacophilidae koje su vezane za vode višeg stupnja kvaliteta.

Tabela 2. Sastav zoobentosa Nahorevskog potoka

Table 2. Content of zoobentic of Nahorevo brook

\begin{tabular}{|c|c|c|c|}
\hline Zoobentos & br.j. & R.A. & $\mathbf{s}$ \\
\hline \multicolumn{4}{|l|}{ CRUSTACEA } \\
\hline \multicolumn{4}{|l|}{ Amphipoda } \\
\hline Gammarus pulex & 2 & 1 & 1,8 \\
\hline \multicolumn{4}{|l|}{ INSECTA } \\
\hline \multicolumn{4}{|l|}{ Ephemeroptera } \\
\hline Baetis rhodani & 5 & 2 & 1,6 \\
\hline Ecdyonurus sp. & 8 & 2 & 1,6 \\
\hline Ephoron virgo & 2 & 1 & 2,3 \\
\hline Paraleptophlebia submarginata & 4 & 2 & 1,9 \\
\hline \multicolumn{4}{|l|}{ Plecoptera } \\
\hline Leuctra sp. & 9 & 2 & 1,3 \\
\hline Protonemura sp. & 3 & 2 & 1,6 \\
\hline Taeniopteryx sp. & 2 & 1 & 1,4 \\
\hline Perlasp. & 1 & 1 & 1,2 \\
\hline \multicolumn{4}{|l|}{ Trichoptera } \\
\hline Hydropsyche sp. & 4 & 2 & 2,5 \\
\hline Cheumatopsiche lepida & 2 & 1 & 1,9 \\
\hline Plectrocnemia conspersa & 4 & 2 & 1,5 \\
\hline Rhyacophila tristis & 3 & 2 & 1,4 \\
\hline \multicolumn{4}{|l|}{ Diptera } \\
\hline \multicolumn{4}{|l|}{ Chironomidae } \\
\hline Orthocladinae & 8 & 2 & 2,1 \\
\hline \multicolumn{4}{|l|}{ Coleoptera } \\
\hline 1.2 Elmidae & 3 & 2 & 1,5 \\
\hline$\Sigma$ broj jedinki & & 60 & \\
\hline$\Sigma$ broj taksona & & 15 & \\
\hline
\end{tabular}


Iz procentulanog učešća sastava invertebrata u sastavu zoobentosa Nahorevskog potoka vidljivo je da su vodeni cvjetovi (graf.1) prisutni najvećim procentom $(32 \%)$. Visokim procentom zastupljene su i kamenjarke (25\%) kao i vodeni moljci $(23 \%)$.

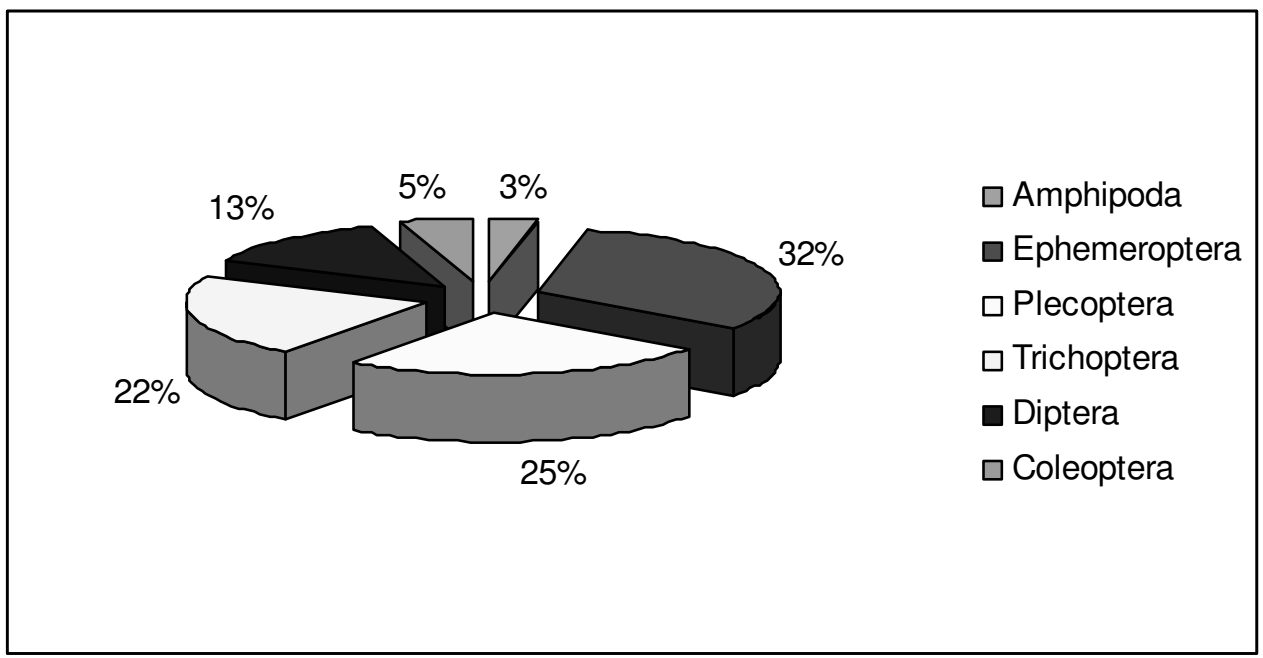

Graf.1. Učešće (\%) invertebrata u sastavu zoobentosa Nahorevskog potoka Graf 1. Percetage (\%) the invertebrats in the zoobentic content of Nahorevo brook

Kvalitet vode

Dobivena vrijednost saprobnog indeksa je 1,57 što svrstava vodu Nahorevskog potoka u kategoriju oligo/ betamesosaprobne i li I/II kategoriju boniteta.

\section{Rezultati morfometrijskih mjerenja potočnog raka sa kondicionim indeksom - Results of morphometrical measurements of stone crayfish with condition index}

Za potrebe upoznavanja osnovnih bioloških karaktreristika raka kamenjara vršena su mjerenja slijedećih parametara: totalne dužine (TL) i totalne težine tijela $(W)$, dužine karapaksa $(\mathrm{CL})$, širine karapaksa $(\mathrm{CW})$, dužine rostruma (CHL), širine rostruma $(\mathrm{CHW})$, dužine kliješta (SL) kao i odnos spolova datih jedinki. Rezultati su prikazani tabelarno, zajedno sa srednjom vrijednosti, posebno za mužjake (pet jedinki) i ženke (šest jedinki).

Prema dobivenim vrijednostima izračunata je aritmetička sredina za date parametre, koja je prikazana na dnu svake tabele. Urađene su tabele posebno za mužjake i ženke kao i posebna tabela sa istim vrijednostima za sve jedinke. Analizirano je šest jedinki ženki, najveća težina tijela (W) 9, 22 g kod jedinke broj 1, a najmanja $0,73 \mathrm{~g}$ kod jedinke broj 6 . Srednja vrijednost težine tijela je 4,836 g za ženke. Najduže tijelo (TL) je $7 \mathrm{~cm}$ kod ženke 1 a najmanja je $4,5 \mathrm{~cm}$ (jedinke 5 i 6), dok je srednja dužina tijela $5,73 \mathrm{~cm}$. Najveća dužina kliješta je $2,5 \mathrm{~cm}$ (jedinka broj 
1), i to je najkrupnija ženka, a najmanja $1,2 \mathrm{~cm}$ kod ženke broj 6. Srednja vrijednost dužine kliješta je $1,86 \mathrm{~cm}$. Najširi karapaks $(\mathrm{CW})$ je $1,8 \mathrm{~cm}$ (jedinka 1 ), dok je najuži karapaks 1,4 cm (jedinka 6). Srednja vrijednost dužine karapaksa je 1,45 cm. Najduži karapaks (CL) je uočen kod jedinke $1(3,4 \mathrm{~cm})$ a najkraći karapaks je 2,1 cm kod jedinki 5 i 6, dok je srednja vrijednost dužine karapaksa 2,683 cm. Najveća širina rostruma $(\mathrm{CHW})$ je $0,7 \mathrm{~cm}$, uočena kod jedinke 1 , dok je najuži rostrum $0,4 \mathrm{~cm}$ (jedinke 4 i 6). Srednja vrijednost za širinu rostruma ženki iznosi $0,523 \mathrm{~cm}$. Najduži rostrum od (CHL) 0,8 cm uočen je kod jedinke 1, a najkraći iznosi 0,5 (ženke 5 i 6), dok je srednja vrijednost dužine rostruma za ženke $0,41 \mathrm{~cm}$.

Tabela 3. Vrijednosti morfoloških karakteristika kod ženki raka kamenjara Austropotamobius torrentium iz Nahorevskog potoka

Table 3. Values of female crayfish's mophologic characteristics from Nahorevo brook

\begin{tabular}{|ccccccccc|}
\hline $\begin{array}{c}\text { Broj } \\
\text { jedin. }\end{array}$ & Spol & $\begin{array}{c}\text { Težina } \\
\text { tijela } \\
(\mathrm{g})\end{array}$ & $\begin{array}{c}\text { Dužina } \\
\text { tijela } \\
(\mathrm{cm})\end{array}$ & $\begin{array}{c}\text { Dužina } \\
\text { kliješta } \\
(\mathrm{cm})\end{array}$ & $\begin{array}{c}\text { Širina } \\
\text { karapaksa } \\
(\mathrm{cm})\end{array}$ & $\begin{array}{c}\text { Dužina } \\
\text { karapaksa } \\
(\mathrm{cm})\end{array}$ & $\begin{array}{c}\text { Širina } \\
\text { rostruma } \\
(\mathrm{cm})\end{array}$ & $\begin{array}{c}\text { Dužina } \\
\text { rostruma } \\
(\mathrm{cm})\end{array}$ \\
\hline 1 & $\mathrm{f}$ & 9,22 & 7 & 2,5 & 1,8 & 3,4 & 0,7 & 0,8 \\
2 & $\mathrm{f}$ & 7,96 & 6,8 & 2 & 1,5 & 3 & 0,65 & 0,7 \\
3 & $\mathrm{f}$ & 5,77 & 6,5 & 2,8 & 1,5 & 3 & 0,5 & 0,7 \\
4 & $\mathrm{f}$ & 3,23 & 5,1 & 1,5 & 1 & 2,5 & 0,4 & 0,5 \\
5 & $\mathrm{f}$ & 2,11 & 4,5 & 1,2 & 1,5 & 2,1 & 0,49 & 0,5 \\
6 & $\mathrm{f}$ & 0,73 & 4,5 & 1,2 & 1,4 & 2,1 & 0,4 & 0,41 \\
$\mathbf{X}$ & & 4,836 & 5,73 & 1,86 & 1,45 & 2,683 & 0.523 & 0,6 \\
\hline
\end{tabular}

Kod mužjaka je analizirano pet jedinki, najveća težina tijela $(\mathrm{W})$ iznosi $8,09 \mathrm{~g}$ (mužjak 1), a najmanja 1,54 g (mužjak 5). Srednja vrijednost težine tijela iznosi 5,938 g. Najveća dužina tijela (TL) kod mužjaka $7 \mathrm{~cm}$ je izmjerena kod jedinke 1, a najmanja 3,3 cm kod jedinke 5, dok je srednja vrijednost dužine tijela kod mužjaka $5,75 \mathrm{~cm}$. Najveća dužina kliješta je 2,3 cm (jedinka broj 1), i to je najkrupniji mužjak, a najmanja je $0,9 \mathrm{~cm}$ (jedinka 5), dok je srednja vrijednost za dužinu kliješta je 1,8 $\mathrm{cm}$. Najširi karapaks (CW) je 2,2 cm (jedinka 1), dok je najuži karapaks $0,9 \mathrm{~cm}$ (jedinka 6). Srednja vrijednost dužine karapaksa je 1,64 cm. Najduži karapaks je uočen kod jedinke 1 i iznosi 3,3 cm, a karapaks je 1,5 cm kod jedinke 5. Dok je srednja vrijednost dužine karapaksa $2,7 \mathrm{~cm}$. Najveća širina rostruma je $0,61 \mathrm{~cm}$, uočena kod jedinke 2 , dok je najuži rostrum $0,3 \mathrm{~cm}$ (jedinka 5). Srednja vrijednost za širinu rostruma mužjaka iznosi $0,482 \mathrm{~cm}$. Najduži rostrum dug $0,8 \mathrm{~cm}$ uočen je kod jedinke 1 , a najkraći iznosi $0,35 \mathrm{~cm}$ (mužjak 5). Srednja vrijednost dužine rostruma iznosi $0,41 \mathrm{~cm}$. 
Tabela 4. Vrijednosti morfoloških karakteristika kod mužjaka raka kamenjara Austropotamobius torrentium iz Nahorevskog potoka

Table 4. Values of male crayfish's mophologic characteristics from Nahorevo brook

\begin{tabular}{|ccccccccc|}
\hline $\begin{array}{c}\text { Br. } \\
\text { jed. }\end{array}$ & Spol & $\begin{array}{c}\text { Težina } \\
\text { tijela } \\
(\mathrm{g})\end{array}$ & $\begin{array}{c}\text { Dužina } \\
\text { tijela } \\
(\mathrm{cm})\end{array}$ & $\begin{array}{c}\text { Dužina } \\
\text { kliješta } \\
(\mathrm{cm})\end{array}$ & $\begin{array}{c}\text { Širina } \\
\text { karapaksa } \\
(\mathrm{cm})\end{array}$ & $\begin{array}{c}\text { Dužina } \\
\text { karapaksa } \\
(\mathrm{cm})\end{array}$ & $\begin{array}{c}\text { Širina } \\
\text { rostruma } \\
(\mathrm{cm})\end{array}$ & $\begin{array}{c}\text { Dužina } \\
\text { rostruma } \\
(\mathrm{cm})\end{array}$ \\
\hline 1 & $\mathrm{~m}$ & 8,09 & 7 & 2,3 & 2,2 & 3,3 & 0,6 & 0,8 \\
2 & $\mathrm{~m}$ & 8,03 & 6,66 & 2 & 1,8 & 3,3 & 0,61 & 0,7 \\
3 & $\mathrm{~m}$ & 8,29 & 6,5 & 2,1 & 1,8 & 3,1 & 0,5 & 0,6 \\
4 & $\mathrm{~m}$ & 3,74 & 5,3 & 1,7 & 1,5 & 2,3 & 0,4 & 0,5 \\
5 & $\mathrm{~m}$ & 1,54 & 3,3 & 0,9 & 0,9 & 1,5 & 0,3 & 0,35 \\
$\mathbf{X}$ & & 5,938 & 5,75 & 1,8 & 1,64 & 2,7 & 0,482 & 0,59 \\
\hline
\end{tabular}

b) Rezultati statističke obrade podataka - The results of the statistical data treatment

Prema dobivenim vrijednostima izračunata je aritmetička sredina, standardna devijacija i varijansa. Rezultati su prikazani zajedno za sve jedinke (tab. 5) kao i odvojeno za mužjake i ženke (tab. 6 i 7).

Dobivene vrijednosti (tab. 5) ukazuju da je prosječna težina tijela za svih jedanaest jedinki $5,337 \mathrm{~g}$, dužina $5,74 \mathrm{~cm}$, a dužina kliješta $1,836 \mathrm{~cm}$. Prosječna širina karapaksa je $1,536 \mathrm{~cm}$ i dužina $2,69 \mathrm{~cm}$, dok je prosječna širina rostruma $0,504 \mathrm{~cm}$, a dužina iznosi $0,596 \mathrm{~cm}$.

$\mathrm{Na}$ osnovu ovih vrijednosti dobivena je standardna devijacija (S), koja ima najveću vrijednost za težinu tijela $(3,141)$, dužinu tijela $(1,262)$, te nešto manje za dužinu karapaksa $(0,613)$, dužinu kliješta $(0,474)$, širinu karapaksa $(0,369)$ te najmanje za dužinu rostruma $(0,155)$ i širinu rostruma $(0,124)$. Vrijednosti težine tijela najviše variraju što pokazuje dobivena vrijednost koeficijenta varijabilnosti $(58,85 \%)$, dok je najmanje variranje u dužini tijela $(21,98 \%)$.

Tabela 5. Vrijednosti statističkih parametara za sve jedinke potočnog raka (11) iz Nahorevskog potoka Table 5. Values of statistical parametres for every sample of stone crayfish(11) from Nahorevo brook

\begin{tabular}{|llllcl|}
\hline $\begin{array}{l}\text { Morfološke } \\
\text { karakteristike }\end{array}$ & Min. & Max. & X & S & V\% \\
\hline Težina tijela(g) & 0,73 & 9,22 & 5,337 & 3,141 & 58,85 \\
Dužina tijela(cm) & 3,3 & 7 & 5,74 & 1,262 & 21,98 \\
Dužina kliješta(cm) & 0,9 & 2,8 & 1,836 & 0,474 & 25,82 \\
Širina karapaksa(cm) & 0,9 & 2,2 & 1,536 & 0,369 & 24,02 \\
Dužina karapaksa(cm) & 1,5 & 3,4 & 2,69 & 0,613 & 22,78 \\
Širina rostruma(cm) & 0,3 & 0,7 & 0,504 & 0,124 & 24,6 \\
Dužina rostruma(cm) & 0,35 & 0,8 & 0,596 & 0,155 & 26,01 \\
\hline
\end{tabular}


Dobivene vrijednosti (tab. 6) ukazuju da je kod ženki vrijednost (prosječna) težine tijela $5,938 \mathrm{~g}$, dužine tijela $5,752 \mathrm{~cm}$, dužine kliješta $1,8 \mathrm{~cm}$, širine karapaksa 1,64 $\mathrm{cm}$, dužine karapaksa $2,7 \mathrm{~cm}$, širine rostruma $0,482 \mathrm{~cm}$ i dužine rostruma $0,59 \mathrm{~cm}$.

$\mathrm{Na}$ osnovu ovih vrijednosti dobivena je standardna devijacija koja ima najveću vrijednost za težinu tijela $(3,11)$, nešto manju za dužinu tijela $(1,513)$, zatim dužinu karapaksa $(0,62)$, dužinu kliješta $(0,5477)$, širinu karapaksa $(0,48)$, dužinu rostruma $(0,1746)$, dok je najmanja za širinu rostruma $(0,133)$.

Vrijednosti dužine karapaksa najmanje variraju što pokazuje dobivena vrijednost koeficijenta varijabilnosti $(22,96 \%)$, dok je najveće variranje u težini tijela $(52,374 \%)$.

Tabela 6. Vrijednosti nekih statističkih parametara za jedinke potočnog raka (pet mužjaka) iz Nahorevskog potoka

Table 6. Values of some statistical parametres for sample of stone crayfish(5 males) from Nahorevo brook

\begin{tabular}{|llllll|}
\hline $\begin{array}{l}\text { Morfološke } \\
\text { karakteristike }\end{array}$ & Min. & Max. & X & S & V\% \\
\hline Težina tijela(g) & 1,54 & 8,09 & 5,938 & 3,11 & 52,374 \\
Dužina tijela(cm) & 3,3 & 7 & 5,752 & 1,513 & 26,30 \\
Dužina kliješta(cm) & 0,9 & 2,3 & 1,8 & 0,5477 & 30,427 \\
Širina karapaksa(cm) & 0,9 & 2,2 & 1,64 & 0,48 & 29,43 \\
Dužina karapaksa(cm) & 1,5 & 3,3 & 2,7 & 0,62 & 22,96 \\
Širina rostruma(cm) & 0,3 & 0,61 & 0,482 & 0,133 & 27,51 \\
Dužina rostruma(cm) & 0,35 & 0,8 & 0,59 & 0,1746 & 29,59 \\
\hline
\end{tabular}

Dobivene vrijednosti (tab. 7) za mužjake ukazuju da je prosječna vrijednost težine tijela $4,836 \mathrm{~g}$, dužine tijela $5,73 \mathrm{~cm}$, dužine kliješta $1,86 \mathrm{~cm}$, širine karapaksa 1,45 $\mathrm{cm}$, dužine karapaksa $2,683 \mathrm{~cm}$, širine rostruma $0.523 \mathrm{~cm}$ i dužine rostruma $0,6 \mathrm{~cm}$.

Standardna devijacija ima najveću vrijednost za težinu tijela $(3,367)$. Nešto manje vrijednosti su za dužinu tijela $(0,869)$, dužinu kliješta $(0,653)$, dužinu karapaksa $(0,5344)$, širinu karapaksa $(0,2588)$, dužinu rostruma $(0,1523)$ i najmanja vrijednost je za širinu rostruma $(0,1258)$.

Vrijednosti težine tijela kod ženki najviše variraju, što pokazuje dobivena vrijednost koeficijenta varijabilnosti $(69,62 \%)$, dok je najmanje variranje u dužini tijela $(15,17 \%)$. 
Tabela 7. Vrijednosti nekih statističkih parametara za jedinke potočnog raka (šest ženki) iz Nahorevskog potoka

Table 7. Values of some statistical parametres for samples of stone crayfish(6 females) from Nahorevo brook

\begin{tabular}{|llllll|}
\hline Morfološke karakteristike & Min. & Max. & X & S & V\% \\
\hline Težina tijela $(\mathbf{g})$ & 0,73 & 9,22 & 4,836 & 3,367 & 69,62 \\
Dužina tijela(cm) & 4,5 & 7 & 5,73 & 0,869 & 15,17 \\
Dužina kliješta(cm) & 1,2 & 2,5 & 1,86 & 0,653 & 35,11 \\
Širina karapaksa(cm) & 1 & 1,8 & 1,45 & 0,2588 & 17,85 \\
Dužina karapaksa(cm) & 2,1 & 3,4 & 2,683 & 0,5344 & 19,92 \\
Širina rostruma(cm) & 0,4 & 0,7 & 0.523 & 0,1258 & 24,05 \\
Dužina rostruma(cm) & 0,41 & 0,8 & 0,6 & 0,1523 & 25,38 \\
\hline
\end{tabular}

\section{c) Kondicioni indeks (stupanj kondicije)}

Izračunata su dva stupnja kondicije (CC i FCF) na osnovu navedenih formula. Najmanji CC je 0,023 (kod mužjaka), a najveći 0,042. Srednja vrijednost je za ženke 0,021 a za mužjake 0,029 .

Najmanji FCF je 0,055 (kod ženki), a najveći iznosi 0,346 (kod mužjaka). Srednja vrijednost za ženke je 0,187 , a za mužjake 0,228 .

Tabela 8. Vrijednosti za stupanj kondicije (kondicioni indeks) za jedinke (11) potočnog raka iz Nahorevskog potoka

Table 8. Values for the Condition factor for the samples of stone crayfish from Nahorevo brook

\begin{tabular}{cc|c|c|c|c|c}
\multicolumn{4}{c}{ CC } & \multicolumn{3}{|c}{ FCF } \\
\hline & Min. & Max. & Srednja. & Min. & Max. & Srednja. \\
F & 0,008 & 0,026 & 0,021 & 0,055 & 0,260 & 0,187 \\
\hline \multirow{2}{*}{ M } & 0,023 & 0,042 & 0,029 & 0,159 & 0,346 & 0,228
\end{tabular}

\section{Diskusija - Discussion}

Izmjerena vrijednost $\mathrm{BPK}_{5} 2,48 \mathrm{mg} \mathrm{O}_{2} / 1$ uzrokuje na vodu II stupnja kvaliteta, što je rezultat povećane koncentaracije organske materije alohtonog porijekla $u$ vodotoku (opalog lišća i sl.).

Prema zasićenosti oksigenom (102\%) i koncentraciji rastvorenog oksigena $\left(10,56 \mathrm{mg} \mathrm{O}_{2} / \mathrm{l}\right)$ voda nahorevskog potoka se nalazi u prvoj kategoriji kvaliteta voda.

Zabilježene su visoke vrijednosti amonijaka $(0,48 \mathrm{mg} \mathrm{N} / \mathrm{l})$ što je iznad maksimalno dozvoljene koncetracije za čiste vode. Ovako stanje uzrokovano je utokom otpadnih voda iz staja domicilnog stanovništva. 
Također, što se tiče habitata, možemo reći da se potočni rak najčešće susreće u potocima na većim nadmorskim visinama, tj. u brdskim predjelima, gdje se može uočiti prisustvo kamenja koje mu služi kao zaklon, te na taj način utiče na učestalost raka u tom području. U Austriji je uočena veza između veličine i učestalosti kamenja sa prisustvom potočnog raka kao i prisustva kompeticije za skloništem. Naime, jedinke su preferirale kamenje veće površine, od 300 do $900 \mathrm{~cm}^{2}$, dok se sa daljim povećanjem površine prisustvo potočnog raka smanjivalo (STREISSL, HÖLD, 2002).

Uočena je i veza prisustva rakova i brzine vode rakovi su preferirali brzinu od 0 do $5 \mathrm{~ms}^{-1}$ (STREISSL, HöLD, 2002).

Rezultati istraživanja na populacijama Astacus astacus L. i Austropotamobius pallipes (Lereboullet) su pokazala da su neke morfološke karakteristike (oblik karapaksa, odnosno njegova širina, dužina i zakrivljenost) genetički uvjetovane (SINT, DALLA VIA, FŸrEDER, 2004).

Prosječna dužina tijela jedinki potočnog raka Austropotamobius torrentium u Italiji (Venecija) iznosila je $8 \mathrm{~cm}$, a veoma rijetko dosezala do $12 \mathrm{~cm}$ (DE LUISE, LIBERATO, DI CRISTO, DI COSMO, PAOLUCCI, 2004). U populaciji iz Austrije jedinke su bile duge do 10 cm (PEKNY, HAGER, 2004). U populaciji iz Nahorevskog potoka dužina se kretala u rasponu od 3,3 cm pa do $7 \mathrm{~cm}$ sa prosječnom dužinom tijela $5,74 \mathrm{~cm}$, dok je u populaciji plemenitog raka Astacus astacus iz Boračkog jezera izmjerena prosječna dužina tijela $10,075 \mathrm{~cm}$, sa variranjem od $8,5 \mathrm{~cm}$ do $11,2 \mathrm{~cm}$ (DEDIć, 2005), gdje je očigledno da je Austropotamobius torrentium najmanja vrsta familije Astacidae.

Analizom težine 11 jedinki utvrđena je srednja vrijednost 5,337g, dok je kod osam jedinki plemenitog raka iz Boračkog jezera prosječna težina 34,875 g (DEDIĆ, 2005).

Rezultati analize općih ekoloških uvjeta u kojima egzistira potočni rak u vodama Evrope se, donekle, poklapaju sa uvjetima u Nahorevskom potoku. Ova vrsta je vezana za brdsko/gorski pojas bukovih šuma. Obitava u vodi visokog stupnja kvaliteta (I/II), sa nižom temperaturom $\left(10^{\circ} \mathrm{C}\right)$ i visokim procentom kisika. Totalna dužina jedinki ne prelazi $70 \mathrm{~mm}$, a dužina karapaksa $27 \mathrm{~mm}$. Za vrijeme jednogodišnjih istraživanja zabilježena je veoma malobrojna populacija (11 jedinki), a u toku 2007. godine nije zabilježena niti jedna jedinka. Povećana koncentracija amonijaka, visoka zamućenost vode i prisutan antropogeni utjecaj, uvjetno rečeno, mogli su inicirati izostanak ove vrste u vodi Nahorevskog potoka.

Prema vrijednostima izračunatih indeksa vidljivo je da su mužjaci u boljem kondicionom stanju. To su pokazala i istraživanja kondicionog indeksa kod jedinki potočnog raka u Austriji (STREISSL, HöLD, 2002).

\section{Zaključak - Conclusion}

$\mathrm{Na}$ osnovu rezultata analize općih ekoloških uvjeta u Nahorevskom potoku, habitatu potočnog raka Austropotamobius torrentium, mogu se izvesti slijedeći zaključci:

1. potočni rak je autohtona vrsta za prostor Bosne i Hercegovine; 
2. voda Nahorevskog potoka je, prema sastavu zoobentosa, u kategoriji oligo/betamesosaprobne vode, a prema fizičko-hemijskim uvjetima u I/II kategoriji;

3. vrijednosti totalne dužine i težine ukazuju na variranje dužine od 3,3 do $7 \mathrm{~cm}$ i težine od 0,73 do $9,22 \mathrm{~g}$;

4. maksimalna totalna dužina jedinki potočnog raka u Nahorevskom potoku je 7 $\mathrm{cm}$, a najmanja $0,73 \mathrm{gr}$,

5. konstatiran je veći broj ženki (šest) nego mužjaka (pet);

6. dužina karapaksa kod svih jedinki varira u dijapazonu 1,5 do $3,4 \mathrm{~cm}$ i vezana je sa totalnom dužinom jedinke;

7. primjenjeni indeksi kondicije imaju veće vrijednosti kod mužjaka nego kod ženki;

8. u svom rasprostranjenju potočni rak je vezan za brdsko-gorski predio;

9. veliki utjecaj na egzistenciju potočnog raka ima ljudski faktor, obrađivanja obala, izgradnja vikend naselja i pogoršanje općih abiotičkih uvjeta kako u vodi tako i na obalama vodnih ekosistema;

10. svako apsolutnije zaključivanje o općoj biologiji i ekologiji potočnog raka na prostoru $\mathrm{BiH}$ zahtijeva nastavak istraživanja sa podacima o genskoj komponenti ovih jedinki.

\section{Literatura - References}

1. AdegboYe, D., 1981. The 'Crayfish Condition Factor' a tool in crayfish research. Freshw. Crayfish 5: 154-172.

2. BedJANIČ, M. (2004): Novi podatki o rzširjenosti raka navadnega koščaka Austropotamobius torrentium (Shrank, 1803) v Sloveniji (Crustacea: Decapoda). Natura Sloveniae, 6(1): 25-33.

3. BERTOK, M., BudihnA, N., POVŽ, M. (2003): Strokovne osnove za vzpostavljanje omrežje Natura 2000: ribe (Pisces), piškurji (Cyclostomata), raki deseteronožci (Decapoda): Končno poročilo. Ministarstvo okolje, prostor in energijo, ARSO, Zavod za ribištvo Slovenije, Ljubljana.

4. BertOK, M., BUDIHNA, N., POVŽ, M. SELIŠKAR, T. (2004): Ribe, piškurji, slatkovodni raki deseteronožci. Proteus, 66 (9-10): 462-468.

5. Dedić, M. (2005): Biosistematske karakteristike riječnog raka Astacus astacus Linnaeus, 1785 iz Boračkog jezera: diplomski rad. Prirodno-matematički fakultet Sarajevo, Sarajevo.

6. De Luise, G., Liberato, C., Di Cristo, C., Di Cosmo, A., Paolucci, M. (2004) : Population analysis of Austropotamobius torrentium in the Friuli Venezia Giuli Region. Dept of Biological and Enviromental Sciences, Faculty of Sciences, University of Sannio, Benevento.

7. European native crayfish in relation to land-use and habitat deterioration with a special focus on Austropotamobius torrentium, September 8 - 11, 2004, Innsbruck.

8. Edsman, L., TAUgBóL, T. (2004): Crayfish in Scandinavia - socioeconomic significance and consrevation aspects. Institute of Freshwater Research, 
National Board of Fisheries, Norwegian Institute for Nature Research, Fakkelgaarden, Drottningholm, Lillehammer.

9. Fÿreder, L., Sint, D., Leiter, J., Declara, A. (2004) : Species protection programs on autochthonous crayfish in Tyrol, Austria and Italy. Institute of Zoology and Limnology, University of Innsbruck, Innsbruck.

10. HUBER, M. G. J., SchuBART, C. D. (2004): Genetic analysis of the stone Crayfish (Austropotamobius torrentium) in Germany on the local distribution around Regensburg and the impact of alien crayfish species. Universität Regensburg Leehrstuhl Zoologie, Regensburg.

11. Karaman, M. (1976): Desetonogi rakovi - Decapoda. Prirodonaučen muzej na Makedonija, Skoplje, Fauna na Makedonija II.

12. MATONIČKIN, I. (1991): Beskralješnjaci: biologija viših avertebrata. 2 izd., Školska knjiga, Zagreb.

13. Maguire, I., KlobuČAR, G.I.V., GotStein-MatoČEC, ERBEN, R. (2003): Distrubution of Austropotamobius pallipes (Lereboullet) in Croatia. Bull. Fr. Peche Piscic., 370-371: 57-71.

14. MAGUIRE, I., KLOBUČAR, G.I.V. (2003): Ugrožene autohtone vrste slatkovodnih rakova iz porodice Astacidae u Hrvatskoj. Zoologijski zavod Prirodoslovnomatematičkog fakulteta Sveučilišta u Zagrebu, Zagreb.

15. PUKY, M., SCHAD, P., (2004) : Native and alien Decapoda species in Hungary: distribution, status, conservation importance. Hungarian Danube Research Station of the IEB of the HAS, Varangy Akciocsoport Egyesulet, Göd, Budapest.

16. PeknY, R., HAgeR, J. (2004): A dense population of stone crayfish (Austropotamobius torrentium) under extreme habitat - conditions and its destruction. ARGE ProFisch, Göstling/Ybbs.

17. Petz, B. (!985): Osnovne statističke metode za nematematičare. II izdanje, SNL, Zagreb.

18. RICKER, W. E., 1975. Computation and interpretation of biological statistics of fish populations. Bull. Fish. Res. Bd Can. 191: 1-382.

19. RoelL, M. J. \& D. J. ORTH, 1992. Production of three crayfish populations

20. StREISSL, F., HÖDL, W. (2002): Habitat and shelter requirements of the stone crayfish, Austropotamobius torrentium Schrank. Hydrologia, 477 : 195-199.

21. STREISSL, F., HÖDL,W. (2002): Growth, morphometrics, size at maturity, sexual dimorphism and condition index of Austropotamobius torrentium Schrank. Hydrologia, 477 : 201-208.

22. Sint, D., DALLA VIA, J., FRŸREDER, L. (2004): Morphological variations in Astacus astacus L. and Austropotamobius pallipes (Lereboullet). Institute of Zoology Limnology, University of Innsbruck, Research Centre for Agriculture and Forestry Laimburg, Innsbruck, Ora / Auer.

23. Sket, B. 1996. Austropotamobius torenttium. In: IUCN 2008. 2008 IUCN Red List of Threatened Species. <www.iucnredlist.org $>$. 


\section{Sažetak - Summary}

Over the period from august 2006 and May 2007, we harvested samples of stone crayfish from the Nahorevo stream. We caught a total of 10 units, five males and five females. Te species Austropotamobius torrentium (SHRANK, 1803) inhabits the streams with good quality waters which has been confirmed by this paper. The analysis included general physical/chemical conditions in water (oxygen regime, temperature, conductivity, water hardness, azoth compounds, phosphates). We determined a high level of oxygen, low temperatures, but high values of $\mathrm{BPK}_{5}(2,48 \mathrm{mg} / \mathrm{l})$, which is the result of an increased consumption of oxygen for biodegradation of the present alochton organic matter in the water flow. Based on the analysis of the qualitative and quantitative content of zoobenthics we calculated the saprobe index $(S=1,53)$ which points at cleanliness of the water with insignificant quantity of organic matter. The results of the measurement of lengths of the units of stone crayfish point at the greatest lengths of males and females of up to $7 \mathrm{~cm}$, and the smallest length was bellow one centimeter. The measured lengths of the crayfish coincide with the results from previous reports by StREISSL, F., HöDL,W. 2002, PEKNY, R., HAGER, J. 2004, MAGUIRE, I., KLOBUČAR, G.I.V. 2003. By calculating the variance it was determined that the length in both sexes is the most variable value, and the least variables were determined in the weight of the examined units. The measured values of weight and total length were calculated based on two indexes of condition: Fulton's Conditions Factor (RICKER, 1975), Crayfish Constant, (ADEGBOYE, 1981). Based on the obtained values the conditions existing in the waters of the Nahorevo stream are more favorable for male, which was confirmed by previous studies in Austria (STREISSL, HöLD, 2002). Stone crayfish or stream crayfish Austropotamobius torrentium has been the subject of numerous studies for a lengthier period of time in the region of Europe, including familiarization with biology and ecology of this species. The species does not have the status of saprobe indicator yet, and according to results of the studies, we cannot report, with an absolute certainty, about optimal conditions for its existence. The area of Bosnia and Herzegovina has an abundance of waters and other natural resources and an overall biodiversity, thus, in the future we expect much more comprehensive and extensive data which will give a broader overview of the habitat and density of the crayfish population. The contribution of this paper is in the presentation of the crayfish habitat that has been described as such for the first time in Bosnia and Herzegovina. 